\title{
PowerPACK: A Wireless Power Distribution System for Wearable Devices
}

\author{
Travis Deyle \\ Department of Electrical \\ and Computer Engineering \\ Georgia Institute of Technology \\ Atlanta, GA 30332 \\ tdeyle@gatech.edu
}

\section{Motivation and Related Work}

The field of wireless power transfer (WPT) is very old, dating back to Faraday's discovery of magnetic induction in 1831 and Hertz's demonstration of electromagnetic wave propagation in 1887 [1]. Tesla experimented with large scale wireless power distribution in the early 1900s [2]. Because of continuing demand for practical WPT systems, the field remains active with many recent examples of wireless power transfer systems employing near-field inductive (magnetic) or electric field coupling, including commonly used inductive toothbrush chargers and proximity type RFID tags [3], as well as research systems capable

\author{
Matthew Reynolds \\ Department of Electrical \\ and Computer Engineering \\ Duke University \\ Durham, NC 27708 \\ matt.reynolds@duke.edu
}

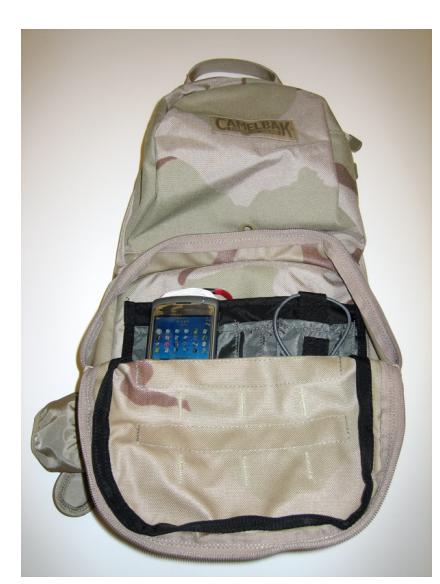

Figure 1: PowerPACK backpack of delivering tens of watts at distances of up to a few meters [4]. There have also been many examples of far-field electromagnetic systems for remotely powering ultra-highfrequency RFID tags [5] or low power sensor and microprocessor circuits [6] at relatively long ranges of up to $3-4 \mathrm{~m}$ in free space.

Motivated by the challenges of conducting pervasive computing research with small, battery powered devices, we have developed a new type of backpack-based power distribution system using the well known principle of nearfield inductive coupling combined with new methods for dynamically optimizing system operation to maintain optimal power transfer. In contrast to high power, long range systems such as [4], we do not intend to supply power at meter-scale distances to a large device such as a power hungry PC or a $60 \mathrm{~W}$ lightbulb. Instead we focus on devices that are typically powered or charged by USB connections, which include a variety of research devices as well as cellphones, iPods, digital cameras, etc. that are USB compliant peripherals. The PowerPACK system, shown schematically in Figure 2, consists of a backpack housing a central power 


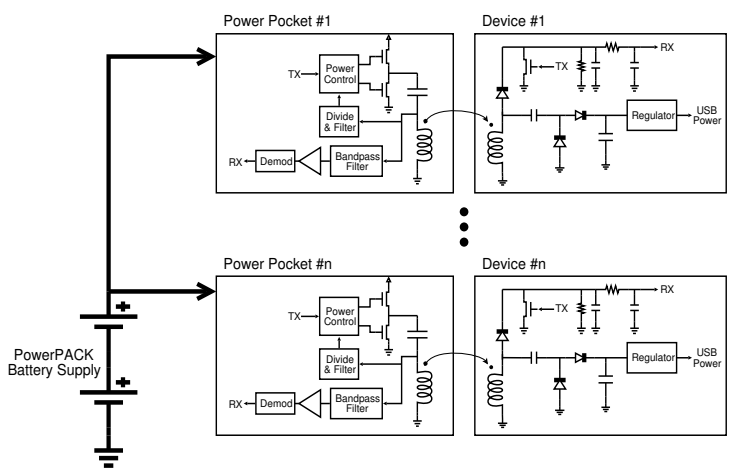

Figure 2: PowerPACK system block diagram

source, in this case a $45 \mathrm{~W} \cdot \mathrm{Hr}$ lithium ion camcorder battery, as well as at least one "power pocket" into which a USB enabled device can be placed for charging. Since there is no cable between the backpack and the endpoint device, devices can be quickly and easily removed and replaced without the need to search for or untangle a particular cable.

In the pervasive computing research context, we envision the PowerPACK system being useful to researchers deploying large numbers of wearable wireless sensors, such as wireless, body-worn accelerometers [8], as well as researchers performing long term studies using cell phones or digital cameras as data collection and computation devices [9], where long run times are crucial for obtaining the desired data set.

Outside of the pervasive computing research context, there are many communities that could derive benefit from the PowerPACK system. Soldiers, for example, carry an increasing number of electronic devices with them, including flashlights, GPS receivers, handheld radios, etc. Each of these devices must be fully charged and ready for use on a moment's notice, but maintaining constant device readiness is difficult due to the large variety of different batteries required for each device [10]. While adequate electrical energy may be available from a certain battery type that the soldier is carrying, that energy is useless if the available battery does not fit whatever device is exhibiting a low battery condition. A common charging infrastructure built into the soldier's backpack could alleviate this problem by distributing power wirelessly without regard to various connectors or intermediate voltages. Building on this notion of a common soldier-carried power bus, the Department of Defense recently announced a Wearable Power Prize of $\$ 1$ million [11] to be awarded to a sub- $4 \mathrm{~kg}(8.8 \mathrm{lb})^{1}$ wearable power source that can deliver $1920 \mathrm{~W} \cdot \mathrm{Hr}$, enough energy for 96

\footnotetext{
${ }^{1}$ Because the required energy density of $1920 \mathrm{~W} \cdot \mathrm{Hr} / 4 \mathrm{~kg}=$ $480 \mathrm{~W} \cdot \mathrm{Hr} / \mathrm{kg}$ far exceeds that of the best currently available rechargeable batteries, the winning power source will most likely be a hybrid consisting of a hydrocarbon engine or fuel cell paired with a lithium ion battery.
}

hours of continuous operation of a set of commonly soldiercarried devices. Soldiers would of course benefit from the easy removal and replacement of endpoint devices without any potentially hazardous delays associated with power cables.

In the civilian sector, working people carry an increasing number and variety of small digital devices with them during their work day. For example, a journalist might carry a cellphone, audio recorder, digital camera, camcorder, GPS receiver, etc. whenever he or she is working. Since each of these devices are likely to use a special battery, many different types of spares would be needed. Unifying these power sources and providing a simple wireless means of recharging would make it easier to ensure that the journalists' devices were always ready to use.

For some users of the PowerPACK, we expect that power generation would be a useful addition to the stored power we employ in our first prototype. This could take the form of a power harvesting or generating system using energy derived from human motion (harvested motion energy), solar power, or power generated by a hydrocarbon engine or a fuel cell.

Regardless of whether stored energy, generated/harvested energy, or some hybrid combination is employed, an important consideration driving the design of the PowerPACK is the tradeoff between decentralized storage or generation versus centralized storage or generation. For stored energy, the internal energy densities of both small and large batteries are approximately equivalent for the same battery chemistry. But packaging considerations result in an economy of scale for larger batteries. For power harvesting and generation systems, economies of scale are even more pronounced. For example, a small piezoelectric or mechanical harvesting system could be mounted directly to each device. For these harvesters, energy generation is on the order of a few tens of milliwatts due to their small proof masses [16]. When a mechanical generating system is scaled to backpack weight of several kilograms, though, power generated while walking can be as high as $7 \mathrm{~W}$ because of the use of the entire backpack mass as the proof mass [17]. Additional related work in wearable power recovery includes mechanical and piezoelectric generators [14] [15] mounted at different locations on the body (e.g. shoes) whose power could be transferred to bulk storage in the backpack.

Solar power is also an attractive option for powering wearable devices, particularly when the user is outdoors in bright sunlight. The DoD has developed a variety of portable solar charging options [10] based on a mixture of military-developed and COTS solutions. COTS solutions available to researchers include a variety of solar chargers designed by outdoor products companies such as Brunton Inc. With solar power, the tradeoffs again favor centralized 
generation and storage using the backpack's entire surface area to generate power. If solar power were employed on each individual device, devices to be charged must be exposed directly to the light, requiring constant user attention to prioritize charging intervals and resulting in mistakes through inconsistent charge times. Precious surface area would also be consumed by the device's user interface surfaces. But if solar power were integrated into a single backpack-scale generating system, solar exposure area would be maximized and an intelligent energy storage system such as the one we have developed for PowerPACK could be used to prioritize device charging.

The choice of common, centralized energy storage and generation/harvesting results in significant improvements in energy density and convenience for the PowerPACK system. The addition of wireless power transfer, though it introduces transmission losses when compared to wired connections, affords the mobile user many benefits- it allows for a single recharge point, provides an auxiliary communication channel, and most importantly, eliminates connectors, multiple battery voltages, and wiring, making the system more robust, more rugged, and lighter. In our first prototype we have focused on the use of lithium ion batteries as they are commonly available, inexpensive compared to other power sources, and well understood, but we expect to include other power sources in future prototypes.

\section{PowerPACK system architecture}

As shown in Figure 2, the PowerPACK system consists of three main parts. The first part is the common power source, which in our prototype is a lithium ion camcorder battery. The second part is the set of wireless power transmitting units, one for each power enabled pocket in the backpack. The third part is the endpoint device power adapter which converts from inductively coupled power to regulated 5V USB power.

\subsection{Common power source}

In our PowerPACK prototype, we use a lithium ion camcorder battery as a common power source. Camcorder batteries were chosen because they exhibit good energy density, and are easily obtained in convenient form factors and voltages. For example, the Sony Model NP-F970 camcorder battery is specified to deliver $7.2 \mathrm{~V}$, with $47.5 \mathrm{~W} \cdot \mathrm{Hr}$ capacity. It weighs $294 \mathrm{~g}$ and therefore delivers an energy density of $162 \mathrm{~W} \cdot \mathrm{Hr} / \mathrm{kg}$, or approximately $1 / 3$ of the energy density required for the Department of Defense prize. Providing a soldier with $1920 \mathrm{~W} \cdot \mathrm{Hr}$ of energy using these batteries would require $40.4 \mathrm{NP}-\mathrm{F} 970$ batteries weighing a total of $11.9 \mathrm{~kg}$ (26lb). The Sony battery is typical for commonly available lithium ion batteries. The Apple MacBook
Pro battery, for example, has $60 \mathrm{~W} \cdot \mathrm{Hr}$ capacity and weighs $447 \mathrm{~g}$, yielding an energy density of $134 \mathrm{~W} \cdot \mathrm{Hr} / \mathrm{kg}$.

In our application we wish to provide power to USB devices, which per the USB specification[12] are permitted to consume up to $5.0 \mathrm{~V}$ DC at $500 \mathrm{~mA}$ peak current, or $2.5 \mathrm{~W}$. A single NP-F970 battery could therefore power a worst-case USB device for 19 continuous hours, assuming $100 \%$ conversion efficiency from battery voltage to 5.0V USB power. At the $80 \%$ power transfer efficiency of our first PowerPACK prototype, we could expect to power a worst-case USB device for 15.2 continuous hours.

\subsection{Power pocket transmitter}

The transmitter side of each power pocket is shown schematically in Figure 3. Most of the digital functions, including power control as well as data transmission and reception, are performed by a Microchip Inc. PIC18F4320 microcontroller, operating at a $40 \mathrm{MHz}$ clock rate. The transmitting coil, shown on the right in both the schematic and the photograph of the first prototype, is selected to exhibit a series resonance with the associated capacitor as close as possible to the desired $125 \mathrm{KHz}$ excitation frequency. This excitation frequency is chosen to comply with FCC regulations, part 15.209 [13]. The use of series resonance in the transmitter results in an increase in the circulating current in the resonant circuit and a correspondingly higher efficiency than would be exhibited by a non-resonant transmitting circuit.

Because of the differing magnetic permeability of various materials, the resonant frequency of the transmitter circuit is often affected by the endpoint device that is placed in the powered pocket. This effect is more or less pronounced depending on the material composition of the endpoint device.

Figure 4(a) shows the variation in transmitting coil voltage $^{2}$ when different devices and materials are inserted into the powered pocket. In Figure 4(b), we present the effect of various device to coil spacing on coil voltage. Since the user may place any object in a powered pocket, including nonpower-enabled devices as well as ordinary materials such as water bottles or keys, our system adapts to the electromagnetic properties of the device placed in the pocket. Because coil current is proportional to the voltage across the coil, and power transmission efficiency increases with increasing coil current, we have implemented an adaptive tuning loop running in software on the PIC microcontroller. The algorithm shown in Figure 5 readjusts the operating frequency of the transmitter every $30 \mathrm{sec}$. to maintain operation at resonance regardless of the object placed in the powered

\footnotetext{
${ }^{2}$ Please note that the relatively high coil voltages shown in the figure are kept well insulated from human contact and do not present any danger to the user.
} 

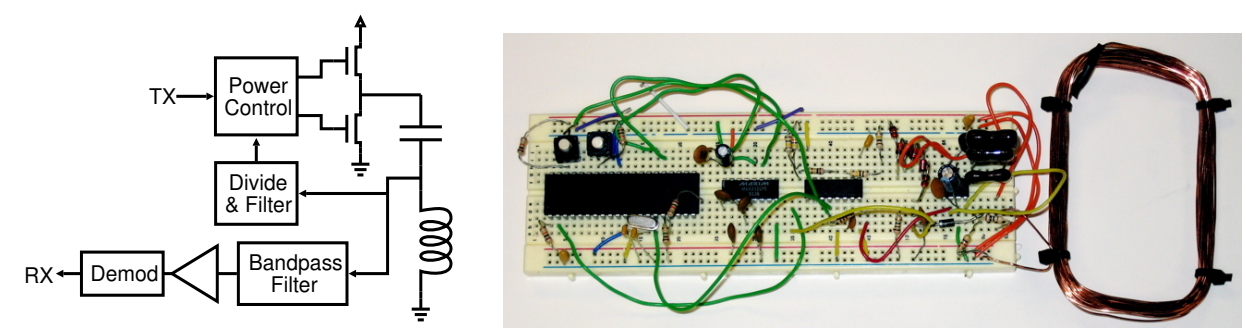

Figure 3: Transmitter section of first transmitter prototype
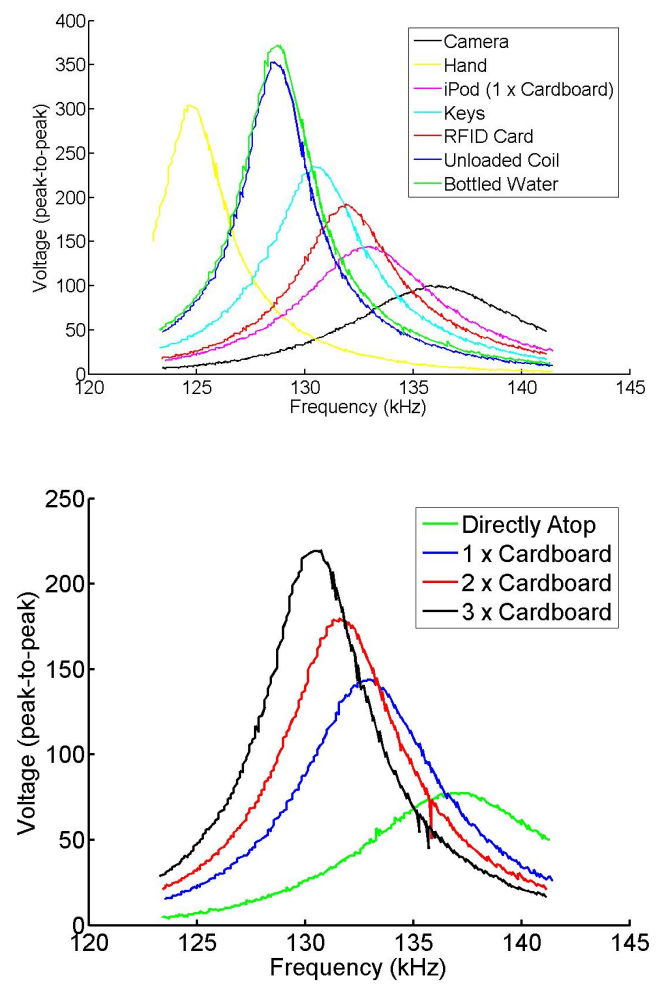

Figure 4: (a) Coil voltage with various devices in the field (b) Coil voltage, Apple iPod Nano in the field, with intervening $3 \mathrm{~mm}$ cardboard spacers

pocket. In addition to the power transfer mechanism, the transmitter is also equipped for bidirectional communication with endpoint devices. The transmitter's output voltage can be amplitude modulated by means of data sent from the PIC microcontroller, and changes in load current from the endpoint device's load modulator can be detected by the bandpass filter and demodulator.

\subsection{Endpoint device adapter}

Figure 6 shows the basic design of the power receiving circuitry attached to each endpoint device, as well as a photograph of the endpoint device adapter as connected to a

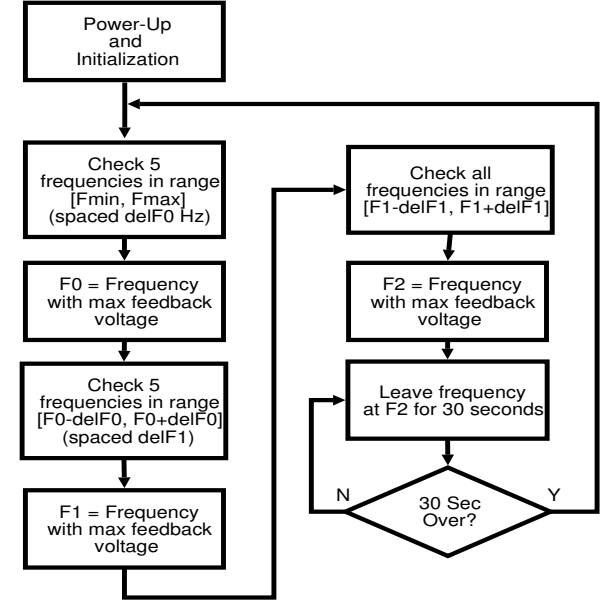

Figure 5: Transmitter adaptive tuning loop that maintains resonance regardless of object in powered pocket

RIM Blackberry smart phone. The endpoint device adapter, in particular, is designed for simplicity and low cost, since one endpoint device adapter is needed for each device that is to be used with the PowerPACK.

The receiving circuitry consists of a coil that matches the endpoint device in size. This coil is the limiting factor in the size of the endpoint device adapter, because the power rectification and conditioning circuitry can easily be designed to consume less than $2 \mathrm{~cm}^{2}$ in board area. The number of turns in the receiving coil is determined by the efficiency and voltage matching considerations presented in Section 3 . The receiving coil voltage is rectified by a voltage doubling rectifier, and regulated to $5.0 \mathrm{~V}$ as required by the USB specification.

In addition to the power rectification circuit, the endpoint device adapter also includes a bidirectional data communication circuit. This circuit consists of two subparts- a receiving circuit, consisting of an envelope detector that detects amplitude modulated data sent from the backpack to the endpoint device, and a load modulator that sends data from the endpoint device to the backpack.

The operation of the communication circuitry, including 
the pocket-to-endpoint and endpoint-to-pocket links, is explained in more detail in Section 4.
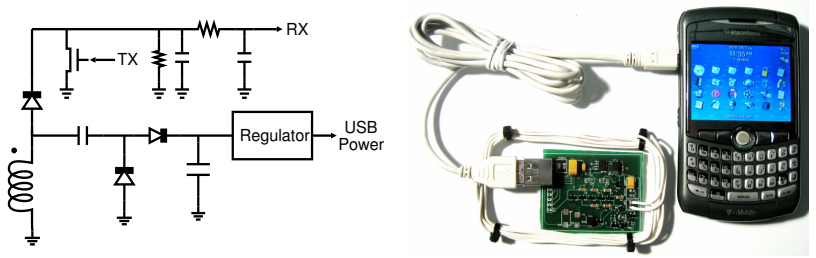

Figure 6: Receiver section and photograph of first endpoint device adapter prototype attached to RIM Blackberry

\section{Evaluation of Available Power and Effi- ciency}

In order to evaluate available power and power transfer efficiency, we performed a system characterization using a single power pocket. The test setup includes a transmission coil designed to resonate at $125 \mathrm{KHz}$, along with two different endpoint device coils. The transmission coil has an inductance of $60 \mu \mathrm{H}$ and was made with 22 turns of solid core, 24AWG magnet wire with a rectangular geometry of $9 \mathrm{~cm} \mathrm{x}$ $5 \mathrm{~cm}$. The first endpoint device coil (Coil 1) has an inductance of $17 \mu \mathrm{H}$ and has 12 turns of solid core, $24 \mathrm{AWG}$ wire with a rectangular geometry of $9 \mathrm{~cm} \times 5 \mathrm{~cm}$. The second endpoint device coil (Coil 2) has the same wire size and shape, but is wound with 22 turns and exhibits an inductance of $51 \mu \mathrm{H}$. Since system performance is highly dependent on the drive circuitry, transmit coil characteristics, and receive coil characteristics, optimization of these parameters are required to achieve best available power and power transfer efficiency. In general, the performance is given in terms of air core transformer equations, though many other factors influence the optimization including transmitter supply voltage, component selection, circuit topology, proximate materials, and geometry. An overview of the underlying physics can be found in [3] and [7].

In our characterization, each endpoint device coil is tightly coupled to the transmission coil through the close spatial proximity achieved when devices are placed in powered pockets. To characterize the available power and efficiency, a static resistive load is attached to the endpoint device coil, and both the power drawn from the central power source by the transmitter and the induced endpoint device voltage are recorded. Using this data, we are able to determine both the power transfer and the efficiency for a variety of resistive loads representing different devices, as shown in Figure 7. The choice of resistive loading is appropriate when the load requires a constant current, as is the case in most battery recharging scenarios. As shown in Figure 7,
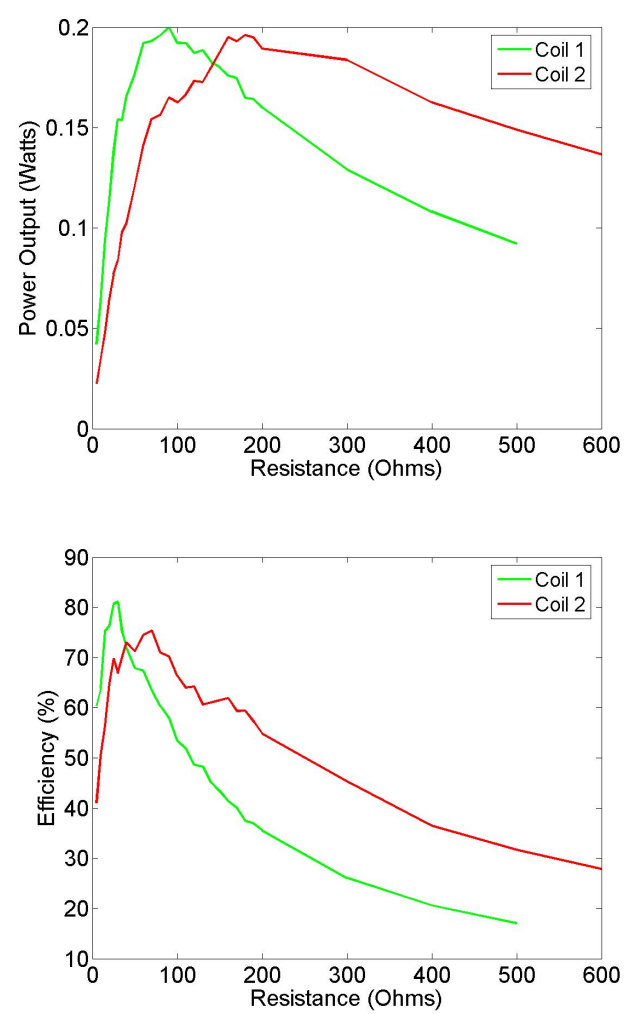

Figure 7: (a) Available power delivered to resistive endpoint device load (b) Power transfer efficiency with resistive endpoint device load

a peak efficiency of $80 \%$ is achieved with a $50 \Omega$ load attached to Coil 1. Peak power transfer occurs with a different load, however, as a peak power of $0.2 \mathrm{~W}$ is transferred with a $100 \Omega$ load. This demonstrates a fundamental tradeoff between maximum power transfer versus maximum efficiency for this type of resonant power transfer system. We summarize our experiments in Table 1, which presents for both endpoint device coils the relationship of power, voltage, and efficiency versus a constant current load. Figure 8 presents the underlying data used to create Table 1.

As shown in Table 1, our initial prototype does not supply the full $2.5 \mathrm{~W}$ peak draw allowed by the USB 2.0 specification. This was not a problem for our initial demonstration because most endpoint devices do not approach the $2.5 \mathrm{~W}$ peak draw in trickle charge mode. The power delivery limitation is due to the particular resonant coil driver IC used in the first prototype, which is shown as the half-bridge pair of MOSFETs in Figure 3. The Microchip Inc. TC4424 halfbridge IC we initially selected has an internal resistance of up to $5 \Omega$, which is the limiting factor in power transfer from the power source to the endpoint device. We will correct this component choice in our next PowerPACK prototype and expect to see significant improvement both in terms of 
Table 1: Efficiency versus endpoint coil selection

\begin{tabular}{|c|c|c|c|}
\hline & Parameter & Peak Efficiency & Peak Power \\
\hline Coil 1: 12 turns & $\begin{array}{l}\text { Transfer Efficiency } \\
\text { Transferred Power } \\
\text { Received Current } \\
\text { Received } \mathrm{V}_{\mathrm{RMS}} \\
\text { Current at } 5 \mathrm{~V} \text { output } \\
\text { (assuming } 90 \% \text { DC-DC efficiency) }\end{array}$ & $\begin{array}{r}81 \% \\
151 \mathrm{~mW} \\
72 \mathrm{~mA} \\
2.1 \mathrm{~V}_{\mathrm{RMS}} \\
27 \mathrm{~mA}\end{array}$ & $\begin{array}{r}57 \% \\
202 \mathrm{~mW} \\
47 \mathrm{~mA} \\
4.3 \mathrm{~V}_{\mathrm{RMS}} \\
36 \mathrm{~mA}\end{array}$ \\
\hline Coil 2: 22 turns & $\begin{array}{l}\text { Transfer Efficiency } \\
\text { Transferred Power } \\
\text { Received Current } \\
\text { Received } \mathrm{V}_{\mathrm{RMS}} \\
\text { Current at } 5 \mathrm{~V} \text { output } \\
\text { (assuming } 90 \% \text { DC-DC efficiency) }\end{array}$ & $\begin{array}{r}75 \% \\
155 \mathrm{~mW} \\
47 \mathrm{~mA} \\
3.3 \mathrm{~V}_{\mathrm{RMS}} \\
28 \mathrm{~mA}\end{array}$ & $\begin{array}{r}59 \% \\
195 \mathrm{~mW} \\
33 \mathrm{~mA} \\
5.9 \mathrm{~V}_{\mathrm{RMS}} \\
35 \mathrm{~mA}\end{array}$ \\
\hline
\end{tabular}

available power as well as power transfer efficiency.

In most mobile situations (i.e. when the PowerPACK is not plugged in and recharging its common power source from a wall outlet), it is desirable to maximize power transfer efficiency when recharging endpoint devices from stored power. Note that at peak efficiency, the RMS voltage available from the endpoint device coil itself is less than the desired 5.0V USB output voltage. This indicates that efficient DC-DC conversion is necessary to maintain the desired 5.0V output at maximum efficiency. The current available, assuming a $90 \%$ efficient power conversion, is shown in Table 1. When plugged in and operating from wall power, the PowerPACK could switch from peak efficiency to peak available power mode, thus delivering more power to rapid charge endpoint devices at the expense of power transfer efficiency.

\section{Communication Implementation and Ap- plications}

Our first PowerPACK prototype provides a low bit rate, auxiliary bidirectional communication channel between a power pocket and its endpoint device at a rate of 10 kilobits per second (Kbps). Communication is half-duplex and employs amplitude modulation in both directions. Figure 9 presents observed data waveforms in both directions. Figure 9(a) shows communication from the endpoint device to the pocket, and Figure 9(b) shows communication from the pocket to the endpoint device. In both cases the data rate is selected by the PIC microcontroller used in the power pocket.

The limit on data communication rate is set by the quality factor $Q$ of the resonant circuit in the pocket transmitter. This resonator acts as a bandpass filter centered around the resonant frequency. Referring to Figure 4(a), the $3 \mathrm{db}$ response bandwidth of the unloaded coil is approximately 3-
$5 \mathrm{KHz}$ so data signals sent much faster than $10 \mathrm{Kbps}$ will be significantly attenuated by the resonant circuit, and significant inter-symbol interference (ISI) will be observed. This will in turn lead to higher bit error rates (BER) on the communication channel and a decrease in the effective communication rate.

We propose a number of useful applications for this communication channel. Perhaps the most obvious application for this channel is to inventory the coupled endpoint devices and detect their presence or absence in specific pockets. A simple binary indication of presence could be used, for example, to issue a reminder to pack up a certain list of endpoint devices when leaving for work in the morning. Similarly, an unexpected loss of a device could cause an audible "theft" alarm.

Another important application for this channel is the management and prioritization of a user's overall power budget. Given a limited supply of stored or generated power worn in the PowerPACK, endpoint devices could transmit their identity and specific power requirements, including endpoint device battery capacity and charging characteristics. The PowerPACK could selectively transfer power to specific endpoint devices, delivering specific amounts of energy based on user-context priorities and remaining backpack capacity.

Consider the following example: A PowerPACK user is traveling, and his or her central battery is running low. Inside the PowerPACK there is a cellphone, portable DVD player, and bluetooth headset that request recharging energy. For emergency preparedness, it is desirable to keep the cellphone completely charged at all times, so it receives the first priority of charging. The bluetooth headset considered a secondary device, and is of little use without a charged cellphone. The DVD player has a low priority as it is considered an entertainment item. In this scenario, the optimal use of PowerPACK energy is to first charge the cell- 

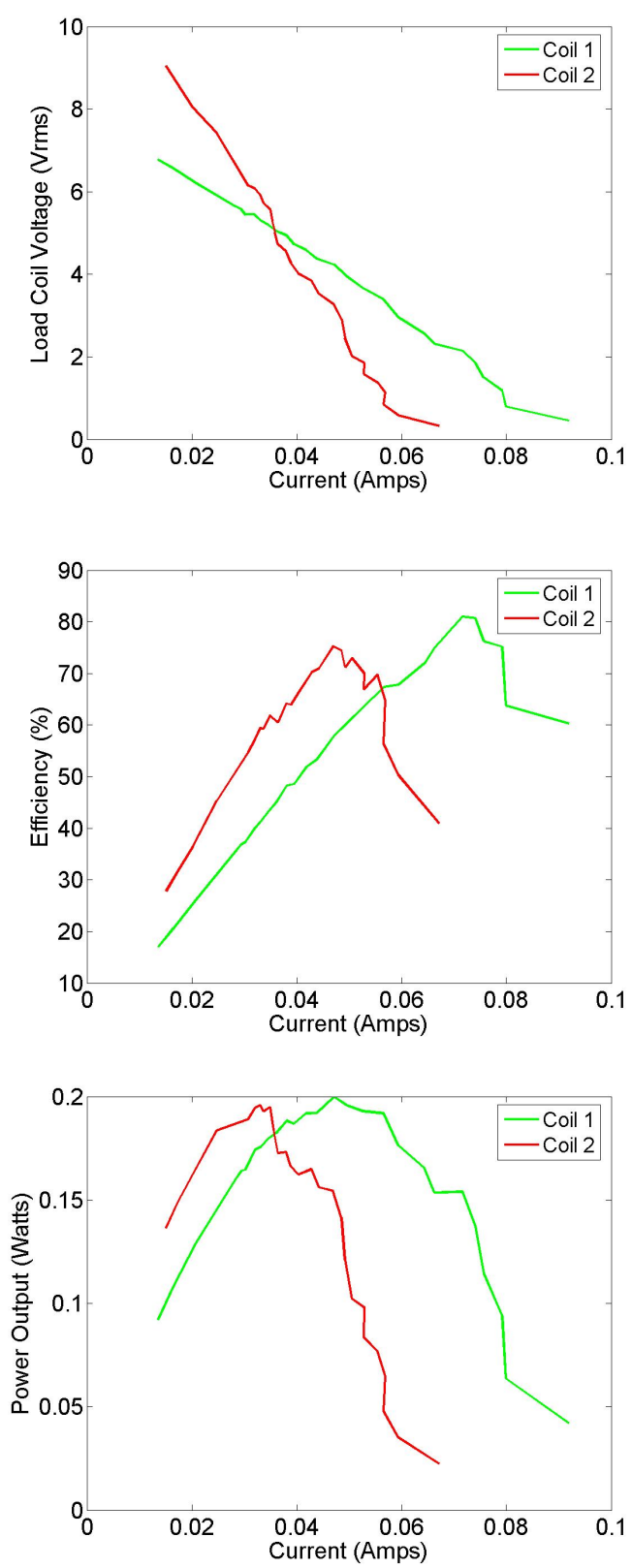

Figure 8: (a) I-V curves for both coils with resistive endpoint device load (b) Power transfer efficiency with resistive endpoint device load (c) Available power versus endpoint device current with resistive load

phone, and then save the remaining PowerPACK capacity in case of an emergency, or the introduction of a new high priority device. When the PowerPACK user returns home and plugs his or her PowerPACK into the wall, the PowerPACK central battery as well as the other two endpoint devices could be recharged. This type of power planning scenario has even more importance for a military user. In a military situation, having a discharged GPS receiver or handheld ra-

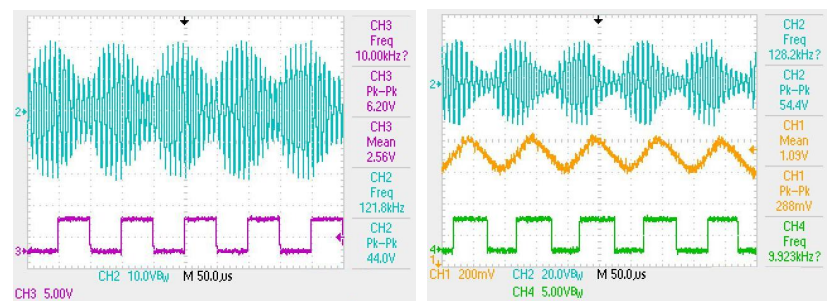

Figure 9: (a) Communication from endpoint device to powered pocket. Top: Transmitter coil voltage showing modulation induced by endpoint device Bottom: Data transmitted by endpoint device (b) Communication from the powered pocket to endpoint device. Top: Transmitter coil voltage modulated by powered pocket transmitted data Middle: Endpoint device envelope detector and filter output Bottom: Data recovered by endpoint device

dio could make the difference between life and death, so these two endpoint devices would receive highest priority.

Using this communication channel, it is also possible to perform two-way cryptographic authentication between the PowerPACK and an inserted endpoint device. A variety of cryptographic challenge-response protocols exist and could be selected for this purpose. Cryptographic authentication between a PowerPACK and an endpoint device would provide two important benefits. First, the endpoint device can be sure of its location within a specific PowerPACK and within a specific pocket, and thus maintain a secure endpoint device usage log. Second, the PowerPACK could be configured to only supply power to a specific set of devices, to prevent unauthorized or unintentional use of both the PowerPACK and the device.

Finally, in addition to a central power supply, the PowerPACK could also possess centralized data storage, available as a utility service to the user. This capability would be particularly useful when performing prolonged user studies where data is captured by endpoint devices. In many recent studies, raw sensor data has been wirelessly transmitted from a sensor to a laptop computer for logging and subsequent analysis. Unfortunately, maintaining a continuous wireless communication link can be power intensive, and wireless data gathering always carries with it the possibility of lost data due to signal dropouts. These power and signal dropout issues are observed in many studies, including [8]. If the PowerPACK also contained a bulk data storage facility, sensors could log data internally into local storage for later offloading when abundant power is available within the PowerPACK. This would provide several advantages for the researcher, including a single recharge point (the PowerPACK) for all sensors, longer run-times for the sensors, and a central data repository for research data. While data could be transmitted using the low-bandwidth 10Kbps link, a better choice would be to exchange Bluetooth pairing or 
WiFi SSID information over the low bandwidth link, and use those high bandwidth communication methods for bulk data exchange.

\section{Conclusion}

The PowerPACK system represents a new type of wearable power distribution system for users of small batterypowered devices. It employs the well known principle of near-field inductive coupling, but improves on prior work through efficiency optimization targeting small, USB class endpoint devices, and the provision of bidirectional data communication. The PowerPACK system distributes power from a single point of generation or bulk storage to a variety of endpoint devices, which can operate from the transferred power or recharge their internal batteries from the central source when they are stowed in a powered pocket in the PowerPACK. Using a $125 \mathrm{KHz}$ resonant inductive coupling mechanism and a dynamic tuning system, we demonstrate a power transfer efficiency of $80 \%$ for small (USB class) device loads.

We present the simultaneous transmission of power from the PowerPACK to an endpoint device, as well as providing a bidirectional communication link between the endpoint device and the backpack. This bidirectional communication link has limited bandwidth (10Kbps), but it has many potential applications, including inventorying coupled devices, prioritization of power delivery to more important devices, detecting the unauthorized removal of a device, authenticating recipients of power, or distributing cryptographic keys for further data exchange using a Bluetooth, WiFi, or another high data rate connection.

\section{References}

[1] Jackson, J. D. Classical Electrodynamics, 3rd Ed. John Wiley, New York, 1998, p. 208.

[2] Tesla, N. "Apparatus for transmitting electrical energy", US Patent \#1,119,732, 1914.

[3] Chen, S., and Thomas, V. "Optimization of inductive RFID technology" in Proceedings of IEEE Symposium on Electronics and the Environment, 2001, pp. 82-87.

[4] Kurs, A., Karalis, A., Moffat, R., Joannopoulos, J.D., Fisher, P., and Soljacic, M. "Wireless power transfer via strongly coupled magnetic resonances" Science, vol. 317, 6 July 2007, pp. 83-86.

[5] Karthaus, U., and Fischer, M., "Fully integrated passive UHF RFID transponder IC with 16.7- $\mu \mathrm{W}$ minimum RF input power" IEEE Journal of Solid-State Circuits, vol.38, no.10, Oct. 2003, pp. 1602-1608.
[6] Smith, J.R., Sample, A.P., Powledge, P.S., Roy, S., and Mamishev, A. "A Wirelessly-powered platform for sensing and computation" in Proceedings of Ubicomp 2006, Springer LNCS 4206, 2006, pp. 495-506.

[7] Jiang, B., Smith, J. R., Philipose, M., Roy, S., Sundara-Rajan, K., and Mamishev, A. "Energy scavenging for inductively coupled passive RFID systems". IEEE Transactions on Instrumentation and Measurement, February 2007, Vol. 56, No. 1, pp. 118-125.

[8] Munguia Tapia, E., Intille, S.S., Lopez, L. and Larson, K. "The design of a portable kit of wireless sensors for naturalistic data collection" in Proceedings of PERVASIVE 2006, Springer LNCS 3968, 2006, pp. 117-134.

[9] Eagle, N., Pentland, A. "Reality mining: sensing complex social systems". Personal and Ubiquitous Computing, Volume 10, Number 4. May, 2006, pp. 255-268.

[10] Brundage, M. "Future trends and thrusts for Army manportable power sources". US Army RDECOM CERDEC, 2007 Joint Service Power Expo, 24-26 April 2007. Available online at: http://www.dtic.mil/ndia/2007power/NDIARegency/Tuesday/ Session32007PowerExpo.pdf

[11] Department of Defense, Office of the Director of Defense Research and Engineering, Wearable Power Prize. Available online at: http://www.dod.mil/ddre/prize/topic.html

[12] Universal Serial Bus 2.0 Specification, released April 27, 2000. Available online at: http://www.usb.org/developers/docs/p. 178.

[13] Federal Communications Commission, Part 15 regulations, released September 20, 2007. Available online at: http://www.fcc.gov/oet/info/rules/part15/part15-9-2007.pdf p.84.

[14] Granstrom, J., Feenstra, J., Sodano, H.A., and Farinholt, K. "Energy harvesting from a backpack instrumented with piezoelectric shoulder straps." Smart Materials and Structures, vol. 16, no. 5, 2007, pp. 1810-1820.

[15] Shenck, N.S., and Paradiso, J.A. "Energy Scavenging with Shoe-Mounted Piezoelectrics.” IEEE Micro, vol. 21, no. 3, 2001, pp. 30-42.

[16] Anton, S.R., and Sodano, H.A. "A review of power harvesting using piezoelectric materials (2003-2006)". Smart Materials and Structures, vol. 16, no 3, 2007. pp. R1-R21.

[17] Rome, L.C., Flynn, L., Goldman, E.M., and Yoo, T.D. "Generating Electricity While Walking with Loads". Science, vol. 309, no. 5741, 2005, pp. 1725-1728. 